\title{
CRÓNICA
}

\section{Cátedra Hispanoamericana Oreste Plath: hacia el renacimiento de la folclorología en Chile}

\author{
por \\ Yvaín Eltit \\ Presidente Sociedad de Folclor Chileno, Chile \\ Director Revista de Folclor Chileno, Chile \\ presidente@folclorchileno.org \\ encinasresecas@gmail.com \\ En memoria de Cora Bindhoff Enet (1905-1995) y \\ Pablo Garrido Vargas (1905-1982)
}

\section{ANTECEDENTES: ORESTE PLATH Y LA ASOCIACIÓN FOLKLÓRICA CHILENA}

El 24 de julio de 1996 fallecía el folclorólogo, escritor, gestor cultural, profesor y museólogo chileno Oreste Plath (nacido con el nombre de César Octavio Müller Leiva el 13 de agosto de 1907 en Santiago), dejándonos el mandato de proseguir su inacabable travesía en aras de nuestro folclor. Para este hombre, que amó a Chile en todas las formas posibles, las tradiciones y la cultura popular no se enfrascaban solo en danza y canto, sino que eran mucho más.

A inicios de 2019, tras conversar con Karen Plath Müller Turina (n. 1946), hija y heredera de Oreste, reavivamos la pasión por el folclor intentando hacer un diagnóstico muy artesanal de la situación en Chile. En el entendido de que, mientras las expresiones populares son cultivadas por los folcloristas, en tanto los folclorólogos somos aquellos que recogemos, registramos, problematizamos y proponemos desde y en torno a nuestro folclor, muy poco o nada se ha hecho por el porvenir del legado de Plath. Qué duda cabe, además, respecto de la carencia de una institucionalidad robusta que se haga cargo de recopilar los saberes con y para el pueblo; más aguda es la crisis cuando la relación folclor y educación está desierta.

Ante este ocaso de la folclorología en Chile, estimamos, en principio, que era un imperativo reactivar la Asociación Folklórica Chilena, entidad que en los años cuarenta buscó hacerse cargo de la vinculación entre folclor y pueblo ${ }^{1}$. Oreste Plath fue uno de sus fundadores y vicepresidente de la Asociación, la que estuvo integrada por nombres emblemáticos como María Luisa Sepúlveda Maira (1883-1958), Aureliano Oyarzún Navarro (1858-1947), Andrés Sabella Gálvez (1912-1989), Josefa Turina Turina (1907-1986), Camila Bari Vélez (1896-1973), Domingo Santa Cruz Wilson (1899-1987), Luis Gómez Catalán (1898-1994), Ismael Edwards Matte (1891-1954), Sady Zañartu Bustos (1893-1983),

${ }^{1}$ La primera sesión de este organismo se efectuó el 3 de febrero de 1943 en dependencias del Museo Histórico Nacional, ubicado en el actual edificio de la Biblioteca Nacional (Moneda 610). Desde septiembre de 1982 este museo se encuentra ubicado en Plaza de Armas 951, en el antiguo edificio de la Real Audiencia. 
Carlos Lavín Acevedo (1883-1962), Cora Bindhoff Enet (1905-1995), Remigio Acevedo Raposo (18961951), entre otros ${ }^{2}$

\section{LA SOCIEDAD DE FOLCLOR CHILENO}

Heredera de la legendaria gesta de Oreste Plath y de la Asociación Folklórica Chilena, la Sociedad de Folclor Chileno fue constituida oficialmente el 29 de enero de 2021 en la Ilustre Municipalidad de Estación Central ${ }^{3}$. Con el legado de Plath como epicentro, el objetivo de esta entidad es abordar, preservar y divulgar la verdadera chilenidad, en un contexto donde lo "moderno" y el "endieciochamiento" parecen dificultar el camino.

Junto con José Manuel Cuadro Maturana, estudiante de historia y director, Nicole Gómez García, periodista y directora, e Igor Bernaola Mateluna, historiador del arte, gestor cultural, buscamos primero el diagnóstico común para hacer efectiva la tarea de continuar con el legado de la Asociación Folklórica Chilena. Así también se ha configurado un consejo consultivo que refleja el sentido transversal, presidido por Karen Plath Müller Turina, experta en arte y folclor; y con los consejeros: el académico y guitarrista clásico Luis Orlandini Robert; la profesora de música y gestora cultural Soledad Minio Pinochet; el historiador Gabriel Salazar Vergara; la académica Carmen Balart Carmona; el organillero Héctor Lizana Hidalgo; el antropólogo e historiador José Bengoa Cabello, la contralto y académica, Carmen Luisa Letelier Valdés, e Isidoro Vázquez de Acuña García del Postigo, historiador, heraldista y genealogista.

Otros miembros (colaboradores) de esta institución son Jorge Hevia Angulo, pianista residente del Teatro Municipal de Santiago; Carlitos Baigo, chef internacional; Claudio Alfaro Arratia, periodista deportivo, y Claudio Aguilera Álvarez, periodista especializado en historia del libro ilustrado e historieta, jefe del Archivo de Láminas y Estampas de la Biblioteca Nacional.

Se ha constituido también un comité editorial integrado por el historiador Pablo Toro Blanco; el poeta huilliche Leonel Lienlaf; el poeta y académico Enrique Winter Sepúlveda, y el lingüista Felipe Hasler Sandoval. Esta estructura operará exclusivamente para la recién restaurada Revista de Folclor Chileno (2022), ya que ganamos el Premio Azul Universidad de Chile, cuyo editor es el joven estudiante de literatura hispánica Marcelo Marilao, de la misma casa de estudios.

También nos honran tres miembros correspondientes: Rafael Jorge Negrete, actor, intérprete de música tradicional mexicana y tenor; Gabriel Medrano de Luna, académico e investigador titular de la Universidad de Guanajuato (México); y María Azucena Colatarci, investigadora y académica (Argentina).

Constituida la Sociedad de Folclor Chileno, el debate estuvo puesto en dónde retomar una agenda que tuviera que ver con aquel pasado ciudadano, recíproco y vinculante con la Asociación Folklórica Chilena, pero conmemorando los veinticinco años del deceso de Oreste. Si la pandemia nos ponía por delante el desafío de adaptarnos a nuevos formatos, emular aquellas emblemáticas semanas de folclor de los años cuarenta y cincuenta se ponía cuesta arriba. La virtualidad permitió transitar a este emergente panorama, el que además podíamos aprovechar llegando a más personas, sin importar latitudes ni lugares, con una propuesta que cumpliera con disciplina y responsabilidad.

\section{LA CÁTEDRA HISPANOAMERICANA ORESTE PLATH}

El espectro académico con toda su pompa y despliegue estuvo amnésico, salvo la Universidad de Talca, casa de estudios donde las últimas actividades de Oreste tuvieron lugar en los años noventa. Después de gestiones con Marcela Albornoz Dachelet (directora de Extensión Cultural y Artística) y el Dr. Álvaro Rojas Marín (rector) se produjo una inédita alianza que dio lugar a convocar a los mejores exponentes del folclor hispanoamericano. De ahí el nombre de esta instancia: Cátedra Hispanoamericana Oreste Plath. Ha sido valioso el patrocinio de instituciones como la Embajada

2 Recientes antecedentes generan interesantes interrogantes acerca del rol del compositor y pintor, Carlos Isamitt Alarcón (1885-1974), así como de Rafael Fernández Rodríguez (1901-1952), estudioso de la zona colchagüina (Sexta Región del Libertador General Bernardo O’Higgins), solo por mencionar algunos.

3 Inscripción N³19983 con documento oficial ratificado el 19 de agosto de 2021. 
de España en Chile, el Centro Cultural de España en Santiago, el diario La Estrella de Valparaíso y la colaboración de la Red de Colegios del Bío-Bío (RedCol), Biblioteca Nacional de Chile, Fundación Nicomedes Guzmán, Centro de Estudios de la Religión de la Universidad Católica (CER-UC) y Museo Patrio General José de San Martín.

La inauguración de la Cátedra tuvo lugar el jueves 25 de marzo de 2021. En palabras del rector Rojas "uno de los nombres que más se asocia con el estudio del folclor y la cultura popular en Chile es, sin duda, el de Oreste Plath, nombre con que fue conocido César Octavio Müller Leiva y a quien nos une como Universidad una larga y cercana relación".

Karen Plath señaló: "Este 2021 se cumplen veinticinco años de su fallecimiento, y Oreste sigue más vigente que nunca. Fue un escritor que abarca tantos temas del folclor, que hoy no se escribe tanto, que por eso sigue tan vigente, porque piensan que el folclor es solo baile y música, y abarca infinitos temas".

Con emoción y entusiasmo contamos con una audiencia desde los más remotos lugares, como Argentina, Colombia, Costa Rica, El Salvador, España, Italia, México, Paraguay, Perú y Uruguay.

El tema tratado fue la figura de la compositora, pianista, violinista y profesora chillaneja María Luisa Sepúlveda Maira (1883-1958). La primera ponencia se tituló "Folklorización y género: una mirada al caso de María Luisa Sepúlveda" y fue presentada por Catalina Sentis Acuña (magíster en Artes mención Música, Pontificia Universidad Católica de Chile, licenciada en Teoría de la Música, licenciada en Educación y profesora de Artes Musicales en la Universidad de Chile) y Javiera Benavente Leiva (licenciada en Teoría de la música de la Universidad de Chile, licenciada en Educación y magíster en Estéticas Americanas de la PUC). Esta conferencia fue una acuciosa puesta en valor de una compositora e investigadora, comprendiendo el contexto en el que vivió María Luisa.

La segunda ponencia fue por parte de quien escribe estas líneas, y la titulé "Oreste y María Luisa: un compromiso conjunto”. Mi interés radicó en expresar la relación de amistad que ambos tuvieron, tanto en sus trabajos de campo como en la arista intelectual. Presenté aportes nunca vistos acerca de María Luisa, como el lugar de su sepultura, información acerca de sus hermanos e interesantes datos respecto de su madre, María Mercedes Maira Gaete. Ella fue una mujer de ideas progresistas para su tiempo, como Oreste nos dijo en un discurso de 1951: "su madre, doña María Mercedes Maira, [fue] poetisa que colaboró en revistas de su época"4.

La segunda sesión de la cátedra tuvo lugar el 21 de abril de 2021 con el tema "Protección e impulso de las expresiones culturales tradicionales como modelo de desarrollo en América Latina”, presentada por Fredy Forero, abogado, coordinador jurídico y derecho de autor del Centro Regional para el Fomento del Libro en América Latina y el Caribe (CERLALC-UNESCO). Esta presentación fue una revisión regional a los proyectos editoriales, las expresiones culturales y nuevas propuestas en torno a cómo debemos abordar tan importante tema desde la esfera pública. Comentaron Magdalena Iraizoz, abogada y directora ejecutiva del Centro de Administración de Derechos Reprográficos Argentina (CADRA) y Roberto Rivera Vicencio, escritor y matemático, presidente de la Sociedad de Escritores de Chile (SECH).

La tercera sesión se realizó el 26 de mayo y el tema fue "Inclusión social, igualdad de género yjuegos tradicionales. Diseño de una metodología innovadora para el trabajo en red”, a cargo de Pere Lavega, presidente de la Asociación Europea de Juegos y Deportes Tradicionales (AEJeST). Su ponencia fue comentada por Gabriel Medrano de Luna, doctor en ciencias sociales y académico de la Universidad de Guanajuato (México), y Verónica Pérez, doctora en antropología ecológica y ambiental, y directora del Instituto para Estudios Mesoamericanos, Universidad de Albany (EE.UU.).

La cuarta sesión se llevó a cabo el 23 de junio con el tema "San Juan Bautista. Aproximación desde la Colección del Museo de los Descalzos del Rimac (Perú)”, presentado por Igor Bernaola Mateluna. Gestor cultural, historiador del arte y curador del Museo de los Descalzos del Rímac (Perú). Esta

4 Evidencia de aquello fueron los aportes que la señora Mercedes entregó al periódico semanal La Mujer (1877), donde no solamente compartió sus pensamientos y versos, sino que fue responsable en Chillán de la misma publicación junto con Elcira Gaete. Este medio de prensa tuvo como épico propósito ser el primero en su rubro en estar gestionado, promovido y publicado directamente por mujeres; se puede leer en las portadas que las autoras abordaban temáticas acerca de "historia, política, literatura, artes, localidad”. Doña Mercedes Maira Gaete falleció el 9 de enero de 1899 por una congestión cerebral. 
instancia consistió en un recorrido virtual y exposición de obras con lienzos y libros sagrados de los siglos XVI, XVII y XVIII.

El 21 de julio fue la quinta sesión, con el tema "Los Archivos del Folclor en Latinoamérica", expuesto por quien escribe estas líneas y comentado por Gabriel Salazar, Premio Nacional de Historia 2006 y consejero de nuestra Sociedad, Claudia Carranza, catedrática del Colegio San Luis (México), y Carlos Molinero, director de la revista Pregón Criollo (Argentina).

El tema de la sexta sesión, el 8 de septiembre, fue "Carlos G. Daws y sus libros de misa. El derrotero de una enciclopedia criolla”, a cargo de Juliana Lozada, antropóloga e investigadora del Museo de Arte Popular José Hernández (Argentina). ${ }^{5}$ Se contó con los comentarios de Sylvia Ríos Montero, investigadora en arte y exdirectora del Museo de Arte Popular Americano (MAPA), Felipe Pinto D'Aguiar, compositor y decano de la Facultad de Arquitectura y Artes de la Universidad Austral de Chile, y Walther Boelsterly, gestor cultural en arte y director general del Museo de Arte Popular-MAP (México).

El 10 de noviembre se realizó la séptima sesión, donde se presentó el tema "Chile, cocinas de pueblos originarios. Herencia y deuda”. La expositora fue Anabella Grunfeld Havas, profesora e investigadora de cocina chilena e integrante de Slow Food Chile, y los comentaristas fueron Cristián Vargas Paillahueque, licenciado en teoría e historia del arte y Magíster (c) en Estudios Latinoamericanos, Universidad de Chile, y Carlos Baigo, chef internacional y miembro de la Sociedad de Folclor Chileno.

Finalmente, la octava y última sesión de 2021 tuvo como tema "Devoción al Niño Jesús en la Colonia”, el que fue presentado por Giovanni Carvajal Farías, estudiante de arte y gestión cultural, Encargado de Proyectos del Museo de Arte Colonial de San Francisco. Esta sesión se realizó el 2 de diciembre.

\section{PROYECCIONES}

Karen Plath Müller Turina, presidenta del Consejo de la Sociedad de Folclor Chileno piensa: "Nunca [Oreste] se podría haber imaginado que por Facebook tiene casi siete mil seguidores, en un medio que no conoció". La virtualidad ha sido el espacio donde el legado de este autor infatigable se difunde y no nos cansamos de dar a conocer y saber más de él. No obstante, el panorama es tensado por la existencia de varios museos en ruinas -que de populares y comunitarios no tienen absolutamente nada-donde el denominado "endieciochamiento" inunda cualquier intento por fomentar iniciativas que escapen a las fronteras de la danza y el canto.

El Ministerio de Educación tampoco ha hecho fácil las cosas, pues en agosto de cada año tanto la asignatura de educación física como el aparato escolar completo son puestos a operar para conmemorar una independencia que nunca fue en septiembre.

Nuestro camino debería ser imitar a otras naciones iberoamericanas que con vigor imparten el folclor como una asignatura obligatoria en los centros educativos. En la enseñanza básica, juegos, canciones, entomología (estudio científico de los insectos), frases y tantas dinámicas podrían expandir la imaginación de los más chicos, orgullosos de donde nacieron, mientras que, en el nivel secundario y superior, el estudio de la cueca podría abordarse no como un baile exótico una vez por año, sino comprendiendo su origen africano por medio de aquel libro capital, Historial de la cueca de Pablo Garrido Vargas. Realizar alguna representación dramática de Antonio Acevedo Hernández (1886-1962) o aprenderse esos versos magníficos del Poema de Chile (1967) de Gabriela Mistral, son otras opciones.

Veinticinco años después de su partida, el sueño de Oreste Plath y la Asociación Folklórica Chilena pervive en la Sociedad de Folclor Chileno, reconstitución de aquella ilustre institución. De esta manera, este texto que podría ser solo un réquiem en honor del legendario folclorólogo que nos ha indicado el rumbo, deviene testimonio de su renacimiento, y la Cátedra Hispanoamericana Oreste Plath es su primera señal.

5 El propósito de esta sesión fue profundizar en torno a la labor de Carlos G. Daws como propulsor de la tradición argentina, lo que fue el antecedente directo para la posterior creación del Museo de Arte Popular José Hernández y su invaluable trabajo y colecciones con las comunidades nacionales. 


\section{BIBLIOGRAFÍA}

Archivo Patrimonial Oreste Plath

Plath, Oreste

2013 [1997] El Santiago que se fue. Apuntes de la memoria. Santiago de Chile: Fondo de Cultura Económica. 2013[1962] Folclor Chileno. Santiago de Chile: Fondo de Cultura Económica

Plath, Oreste (Ed)

Gong Tablero de Arte I/1 (agosto, 1929) (2 páginas, 4 hojas).

\section{RECURSOS WEB}

https://www.utalca.cl/noticias/inaugurada-catedra-hispanoamericana-oreste-plath/

http://www.oresteplath.cl/ 